\title{
Yoga Practice Among Ethnically/Racially Diverse Emerging Adults: Associations with Body Image, Mindful and Disordered Eating, and Muscle-Enhancing Behaviors
}

Dianne Neumark-Sztainer ( $\nabla$ neuma011@umn.edu )

University of Minnesota https://orcid.org/0000-0001-9435-1669

\section{Melanie M Wall}

Columbia University

Jongwoo Choi

Columbia University

Daheia J. Barr-Anderson

University of Minnesota

Marla E. Eisenberg

University of Minnesota

Nicole Larson

University of Minnesota

\section{Research}

Keywords: yoga, eating, weight, eating disorders, body image, steroids, diversity, young adults

Posted Date: July 7th, 2020

DOI: https://doi.org/10.21203/rs.3.rs-40115/v1

License: (c) (i) This work is licensed under a Creative Commons Attribution 4.0 International License. Read Full License 


\section{Abstract}

Background: Yoga may be beneficial for young people at risk for body dissatisfaction and unhealthy behaviors aimed at changing one's body shape and size. This study explores associations between yoga practice and body image, mindful eating, disordered eating, and muscle-enhancing behaviors among a population-based sample of emerging adults from diverse socio-economic and ethnic/racial backgrounds.

Methods: Survey data were collected from 1,568 ethnically/racially diverse emerging adults (18-26 years) as part of the EAT 2010-2018 study (Eating and Activity over Time).

Results: Practicing yoga at least 30 minutes/week was reported by $12.7 \%(n=210)$ of the sample. In models adjusted for sociodemographic characteristics, yoga practitioners had higher levels of mindful eating and body satisfaction than non-practitioners. Of concern, yoga practitioners were more likely to use steroids to enhance the size or tone of their muscles than those not practicing yoga ( $4.2 \%$ vs. $0.8 \%$, $p<.001)$. Furthermore, $35.4 \%$ of yoga practitioners used protein powder or shakes in the past year as compared to $25.0 \%$ of those not practicing yoga $(p=.005)$. Yoga practitioners had similar levels of unhealthy weight control behaviors and binge eating to those not practicing yoga. Associations between yoga practice and body satisfaction, mindful eating, disordered eating, and muscle-enhancing behaviors were similar across ethnic/racial groups.

Conclusions: In order to promote yoga among diverse populations, and enhance its safety and benefits for weightrelated health, it is crucial for settings in which yoga is offered, and yoga teachers, to have awareness of the high prevalence of concerning disordered eating and muscle-enhancing behaviors among students and to address accordingly.

\section{Background}

Body image concerns, disordered eating behaviors, and behaviors aimed at changing one's body shape and size are highly prevalent among adolescents and young adults (1-4). While behaviors such as engaging in physical activity, eating varied nutrient-dense foods, and mindful eating are to be encouraged, other actions such as unhealthy weight control behaviors (e.g., skipping meals, taking diet pills, and self-induced vomiting) and use of muscle enhancers, such as steroids, are problematic $(5,6)$. Research suggests that the prevalence of disordered eating and muscleenhancing behaviors may be equally high, or even higher, among adolescents from lower socio-economic and ethnic/racial minority backgrounds than among adolescents from white and middle or upper socio-economic backgrounds $(2,7-11)$. There is a need for more research on the prevalence, correlates, and use of potentially helpful strategies aimed at promoting a healthy body image and preventing the use of unhealthy behaviors aimed at changing body shape or size among populations that are likely to have been understudied and underserved in terms of prevention and treatment interventions.

Yoga is a mind-body practice that involves physical postures, breathwork, mindfulness, meditation, self-inquiry, and lifestyle practices (12-14). The practice of yoga has several underlying tenets that may assist in promoting a positive body image and a reduction in harmful disordered eating and muscle-enhancing behaviors $(13,15-19)$. For example, yoga encourages making space to come inward to notice what one needs (e.g., more movement, more rest) and then responding in accordance; caring for one's physical, energetic, mental, emotional, and spiritual needs; learning to connect to one's body with kindness and respect; and the promotion of a greater sense of awareness of the body from the inside-out rather than outside-in. Therefore, if young people at risk for body dissatisfaction and unhealthy behaviors aimed at modifying one's body's shape and size can participate in yoga, and the yoga is taught in a sensitive manner, the practice may be helpful. 
The popularity of yoga within westernized societies appears to be growing (20-23). For example, in the United States, practicing yoga over the past year was reported by $9.5 \%$ of adults in 2012 and the prevalence increased to $14.3 \%$ in 2017 (24). The practice of yoga has been shown to be associated with a number of positive physical and emotional health outcomes (25-29). Reviews of research examining the relationships between practicing yoga and body image, disordered eating behaviors, and eating disorders, suggest that yoga may be beneficial, although associations tend to be modest and are not always consistent across studies (16,30-33). For example, in a mixed-methods pilot study examining a yoga-based intervention conducted within an eating disorders treatment center, participants described many positive changes to their body image as a result of their yoga practice (34). College students participating in a yoga program showed decreases in body dissatisfaction and in eating disorder pathology and increases in body appreciation (35). A pilot randomized controlled trial examining the impact of yoga on risk and protective factors for disordered eating among college students found improvements in some outcomes (e.g., positive affect), whereas others (e.g., body dissatisfaction) were not found to be statistically significant (36). Halliwell and colleagues conducted a randomized control trial with undergraduate college female students to assess the impact of a body image centered yoga practice and found the program to be effective in modifying most of the body image outcomes (37). A population-based study of young adults found that yoga practice predicted improvements in body satisfaction over time among those who had lower levels of body satisfaction at a prior assessment (38).

While the body of research on yoga is rapidly growing, there is a dearth of research on the practice of yoga and associations with body image and disordered eating that has been conducted with young people from lower income and diverse ethnic/racial backgrounds (39), particularly outside of the college/university context. Learning more about yoga practice among ethnically/racially diverse populations during the period of transition from adolescence to young adulthood, e.g., emerging adulthood (18-30 years), and associations between yoga and body image, mindful eating, disordered eating, and the use of supplements to change one's muscular shape or size, can provide insight into who is practicing yoga and how best to address their needs. For example, if there is a high prevalence of disordered eating behaviors among those practicing yoga, teachers may need to adapt their language and teaching styles. Likewise, settings where yoga is taught may need to modify the types of products sold and images used in marketing.

The current study aims to address the following research question: How is the practice of yoga associated with various measures of psychological and behavioral health of relevance to the promotion of a healthy body image and the prevention of disordered eating/eating disorders and unhealthy muscle-enhancing behaviors in an ethnically/racially diverse population-based sample of emerging young adults? This study expands on the extant literature in that it explores associations between yoga practice and a broad array of variables, including body satisfaction, body mass index (BMI), mindful eating, extreme and less extreme unhealthy weight control behaviors, binge eating, steroid use, and protein powders/shakes, in an ethnically/racially diverse, population-based sample of emerging young adults. There has been little work examining the practice of yoga in diverse samples of young people, although there have been calls for learning more about diverse populations (39). Furthermore, to the best of our knowledge, some of the variables assessed here, including the use of protein powders/shakes and steroids to enhance muscle size or tone have not been assessed in relation to yoga practice in population-based samples. Given the mixed findings of existing studies (31) and dearth of research examining associations between yoga and such a broad array of outcomes in diverse populations (39), we did not make specific hypotheses with regard to expected associations. Findings will be helpful in informing best practices for yoga practitioners, yoga teachers, and settings in which yoga is taught.

\section{Methods}




\section{Study Design and Population}

Data were collected from 1,568 ethnically/racially diverse emerging adults (mean age $=22.0 \pm 2.0$, range: 1826 years) as part of the EAT 2010-2018 (Eating and Activity over Time) study. EAT 2010-2018 is a population-based, longitudinal study of eating, activity, and weight-related health, and associated factors, in young people. Middle school and senior high school students at 20 urban public schools in Minneapolis-St. Paul, Minnesota completed classroom surveys and anthropometric measures during the 2009-2010 academic year (EAT 2010) $(2,40,41)$. Participants completed follow-up surveys in 2017-2018 (EAT 2018).

Of the original 2,793 participants, 410 (14.7\%) were lost to follow-up, primarily due to missing contact information at EAT 2010 or no current address found at follow-up $(n=397)$. Invitations to participate in EAT 2018 were mailed to the remaining 2,383 young people along with a secure online survey link. Non-responders were mailed up to eight reminders; two of these reminders included paper copies of the survey. Additional contact attempts were made using email, phone calls, text messages, social media messages, and home visits. The University of Minnesota's Institutional Review Board Human Subjects Committee approved all protocols.

The 1,568 young people who completed the consent process and EAT 2018 survey represents $65.8 \%$ of the original, school-based sample for whom current contact information was available at follow-up. Inverse probability weighting (IPW) was used for all analyses to account for missing data $(42,43)$. IPW minimizes potential response bias due to missing data and allows for extrapolation back to the original EAT 2010 school-based sample. Weights for IPW were derived as the inverse of the estimated probability that an individual responded at the two time points based on characteristics reported in 2010, including demographics, past year frequency of dieting, and weight status. Among the analytic sample ( $n=1555$ with non-missing yoga practice responses) the weighted demographics (Table 1) were: 28.7\% African American or Black, 19.9\% Asian American, 18.9\% white, 16.9\% Hispanic, 3.7\% Native American, and $11.9 \%$ mixed or other. Most of the Asian American participants reported Southeast Asian heritage; approximately $79.1 \%$ of this group was Hmong. The weighted distribution across categories of parental socio-economic status (SES) based primarily on formal educational attainment was: $39.3 \%$ low, $22.3 \%$ low-middle, $17.7 \%$ middle, $13.2 \%$ uppermiddle, and $7.5 \%$ high. 
Table 1

Yoga practice (at least 30 minutes/week) by sociodemographic characteristics

\begin{tabular}{|c|c|c|c|c|c|c|c|c|}
\hline & \multirow[b]{2}{*}{$\begin{array}{l}\text { Total N } \\
(\%)^{1}\end{array}$} & \multirow[b]{2}{*}{$\begin{array}{l}\text { Number } \\
\text { practicing } \\
\text { yoga }\end{array}$} & \multicolumn{2}{|c|}{ Unadjusted results } & \multirow{2}{*}{$\begin{array}{l}\text { Model } 1^{3} \\
\begin{array}{l}\text { Adjusted } \\
\% \\
\text { practicing } \\
\text { yoga }\end{array}\end{array}$} & \multicolumn{2}{|c|}{ Model $2^{4}$} & \multirow[b]{2}{*}{$\begin{array}{l}\mathrm{p}- \\
\text { value }\end{array}$} \\
\hline & & & $\begin{array}{l}\% \\
\text { practicing } \\
\text { yoga }\end{array}$ & $\begin{array}{l}\mathrm{p}- \\
\text { value }\end{array}$ & & $\begin{array}{l}\mathrm{p}- \\
\text { value }\end{array}$ & $\begin{array}{l}\text { Adjusted } \\
\% \\
\text { practicing } \\
\text { yoga }\end{array}$ & \\
\hline \multicolumn{9}{|c|}{ Age categories } \\
\hline $18-21$ & $\begin{array}{l}708 \\
(42.9)\end{array}$ & 85 & 11.4 & & 9.9 & 0.187 & 9.1 & \\
\hline $22-25$ & $\begin{array}{l}794 \\
(53.0)\end{array}$ & 116 & 13.5 & 0.380 & 12.3 & & 11.8 & 0.095 \\
\hline $26+$ & $53(4.1)$ & 9 & 15.5 & & 16.3 & & 17.2 & \\
\hline \multicolumn{9}{|l|}{ Gender } \\
\hline Female & $\begin{array}{l}901 \\
(53.2)\end{array}$ & 158 & 17.2 & \multirow[t]{2}{*}{$<.001$} & 17.0 & \multirow[t]{2}{*}{$<.001$} & 16.2 & \multirow[t]{2}{*}{$<.001$} \\
\hline Male & $\begin{array}{l}643 \\
(46.2)\end{array}$ & 48 & 7.2 & & 6.8 & & 6.3 & \\
\hline $\begin{array}{l}\text { Different } \\
\text { identity }\end{array}$ & $11(0.6)$ & 4 & 36.4 & & 32.3 & & 27.1 & \\
\hline \multicolumn{9}{|c|}{ Ethnicity/Race ${ }^{2}$} \\
\hline White & $\begin{array}{l}365 \\
(18.9)\end{array}$ & 56 & 14.6 & \multirow[t]{6}{*}{0.043} & 12.2 & \multirow[t]{6}{*}{0.142} & 11.1 & \multirow[t]{6}{*}{0.268} \\
\hline Black & $\begin{array}{l}340 \\
(28.7)\end{array}$ & 42 & 11.1 & & 10.2 & & 9.8 & \\
\hline Hispanic & 271(16.9) & 36 & 12.4 & & 11.8 & & 11.8 & \\
\hline $\begin{array}{l}\text { Asian } \\
\text { American }\end{array}$ & $\begin{array}{l}353 \\
(19.9)\end{array}$ & 37 & 10.6 & & 10.0 & & 9.3 & \\
\hline $\begin{array}{l}\text { Native } \\
\text { American }\end{array}$ & $62(3.7)$ & 4 & 7.0 & & 7.4 & & 7.5 & \\
\hline Other/Mixed & $\begin{array}{l}164 \\
(11.9)\end{array}$ & 35 & 19.4 & & 17.5 & & 15.8 & \\
\hline
\end{tabular}

Socio-

economic

status
${ }^{1}$ All proportions are weighted for non-response to be representative of the original EAT-2010 sample.
2 Structurally racialized categories labelled by ethnicity/race.
${ }^{3}$ Model 1 is adjusted for age, gender, ethnicity/race, and socio-economic status (SES) ( $n=1518 ; 3.9 \%$ dropped due to missing SES).

${ }^{4}$ Model 2 is additionally adjusted for Body Mass Index (BMI) category ( $n=1483 ; 6.4 \%$ dropped due to missing SES or BMI). 


\begin{tabular}{|c|c|c|c|c|c|c|c|c|}
\hline \multirow[b]{2}{*}{ Low } & \multirow[b]{2}{*}{$\begin{array}{l}558 \\
(39.3)\end{array}$} & \multirow[b]{2}{*}{64} & \multicolumn{2}{|c|}{ Unadjusted results } & \multirow{2}{*}{$\begin{array}{l}\text { Model } \mathbf{1}^{3} \\
9.2\end{array}$} & \multicolumn{2}{|c|}{ Model $2^{4}$} & \multirow[b]{2}{*}{0.045} \\
\hline & & & 10.7 & \multirow[t]{5}{*}{0.038} & & \multirow[t]{5}{*}{0.027} & 8.5 & \\
\hline Low-middle & $\begin{array}{l}332 \\
(22.3)\end{array}$ & 49 & 14.8 & & 13.9 & & 13.6 & \\
\hline Middle & $\begin{array}{l}254 \\
(17.7)\end{array}$ & 29 & 10.9 & & 9.7 & & 9.4 & \\
\hline High-middle & $241(13.2)$ & 39 & 15.6 & & 14.8 & & 13.5 & \\
\hline High & $133(7.5)$ & 26 & 19.2 & & 17.5 & & 15.8 & \\
\hline \multicolumn{9}{|c|}{${ }^{1}$ All proportions are weighted for non-response to be representative of the original EAT-2010 sample. } \\
\hline \multicolumn{9}{|c|}{${ }^{2}$ Structurally racialized categories labelled by ethnicity/race. } \\
\hline \multicolumn{9}{|c|}{$\begin{array}{l}{ }^{3} \text { Model } 1 \text { is adjusted for age, gender, ethnicity/race, and socio-economic status (SES) }(n=1518 ; 3.9 \% \text { dropped due } \\
\text { to missing SES). }\end{array}$} \\
\hline \multicolumn{9}{|c|}{$\begin{array}{l}{ }^{4} \text { Model } 2 \text { is additionally adjusted for Body Mass Index (BMI) category }(n=1483 ; 6.4 \% \text { dropped due to missing } \\
\text { SES or BMI). }\end{array}$} \\
\hline
\end{tabular}

\section{Survey Development and Variables}

Key items from the EAT 2010 survey were retained on the follow-up EAT 2018 survey, while additions were made to assess areas of emerging interest and to reflect participants' transition from adolescence to young adulthood (40, 4446). Focus groups with 29 emerging adults were conducted to pretest the EAT 2018 survey. Test-retest reliability of measures was examined using data from a subgroup of 112 participants who completed the EAT 2018 survey twice within a period of three weeks. All variables utilized in the current analysis, which are described below, were assessed on the EAT 2018 survey unless indicated otherwise.

To assess yoga practice, participants indicated if they had ever done yoga over the past year (yes/no) (test-retest agreement $=89 \%$ ). Those who had ever done yoga were additionally asked, "On average, how frequently did you do yoga over the past year?" Seven response options ranged from "less than $1 \frac{1}{2}$ hour/week" to "10 + hours/week." Respondents who engaged in yoga at least 30 minutes/week were identified as practicing yoga (test-retest agreement $=86 \%)$.

Body Satisfaction was assessed with a modified version of the Body Satisfaction Scale (47). Satisfaction with 13 parts of the body (height, weight, body shape, waist, hips, thighs, stomach, face, body build, shoulders, muscles, chest, overall body fat) was rated using five response categories ranging from "very dissatisfied" to "very satisfied" (Cronbach's alpha $=0.94$; range: $13-65$; test-retest $r=0.80$ ).

Mindful eating was assessed with four items from the Mindful Eating Questionnaire: “I eat so quickly that I don't taste what I'm eating; I snack without noticing that I am eating; Before I eat I take a moment to appreciate the colors and smells of my food; I taste every bit of food that I eat." (48). Each item had four response options. The first two items were reverse scored and items were summed to form a score (range: $4-16$; test-retest $r=0.67$ ).

Unhealthy weight control behaviors were assessed by asking: "Have you done any of the following things in order to lose weight or keep from gaining weight during the past year?" (yes/no for each method). Practices categorized as extremely unhealthy weight control behaviors included 1) took diet pills, 2) made myself vomit, 3) used laxatives, and 
4) used diuretics. Practices categorized as less extreme unhealthy weight control behaviors included 1) fasted, 2) ate very little food, 3) used a food substitute (powder or a special drink), 4) skipped meals, and 5) smoked more cigarettes. Those who responded "yes" for one or more methods were coded as users of extreme (test-retest agreement $=93 \%$ ) and less extreme unhealthy weight control behaviors (test-retest agreement $=76 \%$ ).

Binge eating was assessed with the questions: "In the past year, have you ever eaten so much food in a short period of time that you would be embarrassed if others saw you (binge eating)"? (yes/no). "During the times when you ate this way, did you feel you couldn't stop eating or control what or how much you were eating?" (yes/no). Those who responded "yes" to both questions were categorized as engaging in binge eating (test-retest agreement = 89\%) $(49)$.

To assess muscle-enhancing behaviors, participants were asked: "Have you done any of the following things in order to increase your muscle size or tone during the past year?" and specifically were asked to report (yes/no) on use of protein powder or shakes (test-retest agreement $=88 \%)$ and steroid use (test-retest agreement $=$ not available) $(50-$ $52)$.

Two items individually assessed moderate-to-vigorous physical activity (MVPA): "In a usual week, how many hours do you spend doing the following activities?" (Six response options ranged from none to six or more hours). Strenuous activity was described as activity during which the heart beats rapidly and moderate activity was described as not exhausting. Examples of activities were given after each question (test-retest $r=0.72)(53)$.

Structurally racialized groups (ethnicity/race) were assessed by self-report at baseline with the question: "Do you think of yourself as...? (1) White, (2) Black or African American, (3) Hispanic or Latino, (4) Asian American, (5) Native Hawaiian or Pacific Islander, (6) American Indian or Native American, or (7) Other" (test-retest agreement $=98-100 \%$ ). Since very few participants reported "Hawaiian or Pacific Islander", or did not report their ethnicity/race, they were coded as "mixed/other." SES was determined at baseline and was primarily based on the highest education level of either parent with adjustments made for student eligibility for free/reduced-price school meals, family public assistance receipt, and parent employment status $(54,55)$. On the EAT 2018 survey, participants were given three options for gender. Male, Female, or Different identity (please specify). Age was calculated based on reported birth date and the date of survey completion. BMI was calculated based on self-reported height and weight.

\section{Statistical Analysis}

Descriptive proportions of young adults practicing yoga by sociodemographic characteristics were summarized. Differences across sociodemographic characteristics were tested by logistic regression of yoga practice (yes/no) as the outcome on each characteristic. Models were run unadjusted (e.g., for each sociodemographic characteristic separately); then mutually controlled for all sociodemographic characteristics (Model 1); and finally, additionally controlling for body mass index (BMI) category (<18.5, 18.5-25, 25-30, $\geq 30$ ) (Model 2). Measures of body satisfaction, mindful eating, disordered eating, and unhealthy muscle-enhancing behaviors were all examined in relation to yoga practice using separate regressions of each measure (as the outcome) on yoga practice as the predictor controlling for sociodemographic variables (Model 1) and additionally controlling for BMI category. Continuous measures used linear regression, dichotomous measures used logistic regression. Regression-adjusted means and proportions of each measure are presented by yoga practice as well as effect size differences (standardized mean difference Cohen's d for mean differences, Cohen's h for proportion differences). Effect sizes are used to provide a means for comparing magnitudes across various outcomes on different scales. Commonly used labels to describe Cohen's d and h effect sizes are 0.20 (small), 0.50 (medium), 0.80 (large) effects (56). Additional regression models were fit for each outcome controlling for physical activity and also testing ethnicity/race by yoga interactions. As previously described, to adjust for attrition, all regression analyses and percentages were weighted 


\section{Results}

\section{Yoga practice by sociodemographic characteristics}

Practicing yoga (at least 30 minutes/week) was reported by $12.7 \%(n=210)$ of the study participants. Among these participants, the average frequency of practice was as follows: 30 minutes to less than one hour/week ( $n=68)$; one hour to less than two hours/week $(n=84)$; two to three hours/week $(n=38)$; and four or more hours/week $(n=17)$.

Yoga practice did not differ across age categories. Female young adults were much more likely to practice than male young adults. There was some variation across ethnicity/race, although differences were not statistically significant after adjustment for sociodemographic characteristics and further adjustment for BMI. Young adults from higher socio-economic levels were more likely to practice yoga (Table 1).

\section{Body satisfaction, mindful and disordered eating, and muscle- enhancing behaviors by yoga}

As shown in Table 2, in analyses adjusted for socio-demographic characteristics, young adults practicing yoga had higher levels of body satisfaction (Effect size $(E S)=0.19, p=.020$ ) and mindful eating $(E S=0.22, p=.002)$. Young adults practicing yoga had lower BMI values than young adults not practicing yoga $\left(25.6\right.$ and $27.4 \mathrm{~kg} / \mathrm{m}^{2}$, respectively; $E S=-0.26, p<.001)$. After further adjustment for BMI category, the association between practicing yoga and body satisfaction became negligible $(E S=0.06, p=0.469)$. 
Table 2

Body satisfaction, mindful eating, BMI, disordered eating, and muscle-enhancing behaviors by yoga practice $(\mathrm{n}=$ 1555)

\begin{tabular}{|c|c|c|c|c|c|c|}
\hline & \multirow{2}{*}{\multicolumn{2}{|c|}{$\begin{array}{l}\text { Model } 11 \\
\text { Yoga Practice }\end{array}$}} & \multirow{4}{*}{$\mathrm{ES}^{\mathrm{a}}$} & \multirow{4}{*}{$\begin{array}{l}p- \\
\text { value }\end{array}$} & \multicolumn{2}{|c|}{ Model $2^{2}$} \\
\hline & & & & & \multirow{3}{*}{$\mathrm{ES}^{\mathrm{a}}$} & \multirow{3}{*}{$\begin{array}{l}\mathrm{p}- \\
\text { value }\end{array}$} \\
\hline & No $(n=1334)$ & Yes $(n=209)$ & & & & \\
\hline & $\begin{array}{l}\text { Adjusted }{ }^{1} \text { Mean } \\
(\mathrm{SE}) \text { or } \%(n)\end{array}$ & $\begin{array}{l}\text { Adjusted }{ }^{1} \text { Mean } \\
(\mathrm{SE}) \text { or } \%(\mathrm{n})\end{array}$ & & & & \\
\hline $\begin{array}{l}\text { Body satisfaction (range: } 13- \\
65 \text { ) }\end{array}$ & $42.0(0.34)$ & $44.3(0.94)$ & 0.19 & 0.020 & 0.06 & 0.469 \\
\hline $\begin{array}{l}\text { Mindful eating } \\
\text { (range: 4-16) }\end{array}$ & \multicolumn{5}{|c|}{ (range: $4-16)$} & 0.006 \\
\hline BMI (kg/m2) & $27.4(0.2)$ & $25.6(0.45)$ & -0.26 & $<001$ & - & - \\
\hline $\begin{array}{l}\text { Extreme unhealthy weight } \\
\text { control behaviors }\end{array}$ & $11.7 \%(177)$ & $10.0 \%(25)$ & 0.06 & 0.473 & -0.01 & 0.962 \\
\hline $\begin{array}{l}\text { Less extreme unhealthy weight } \\
\text { control behaviors }\end{array}$ & $51.0 \%(671)$ & $55.9 \%(118)$ & 0.10 & 0.225 & 0.24 & 0.010 \\
\hline Binge eating & 10.9\% (159) & $10.3 \%(28)$ & -0.02 & 0.786 & 0.04 & 0.602 \\
\hline Steroid use & $0.8 \%(14)$ & $4.2 \%(10)$ & 0.23 & $<.001$ & 0.22 & $<.001$ \\
\hline Protein powder/shakes & $25.0 \%(338)$ & $35.4 \%(66)$ & 0.23 & 0.005 & 0.22 & 0.007 \\
\hline \multicolumn{7}{|c|}{$\begin{array}{l}{ }^{1} \text { Model } 1 \text { is adjusted for age, gender, ethnicity/race, and socio-economic status. Adjusted Mean (SE) and \% by } \\
\text { yoga status for each outcome are the expected mean outcomes from the regression Model } 1 \text { with socio- } \\
\text { demographics fixed at their respective sample means. }\end{array}$} \\
\hline \multicolumn{7}{|c|}{2 Model 2 is additionally adjusted for Body Mass Index category. } \\
\hline \multicolumn{7}{|c|}{$\begin{array}{l}\text { a ES is effect size provides a comparable measure of magnitude across outcomes. It is calculated as the } \\
\text { standardized mean difference Cohen's d (for continuous outcomes) and a scaled difference in proportions Cohen's } \\
\text { h (for dichotomous outcomes). }\end{array}$} \\
\hline
\end{tabular}

Regardless of yoga practice, high percentages of study participants engaged in disordered eating behaviors (Table 2). In analyses adjusted for socio-demographic characteristics, yoga was not associated with these disordered eating variables. Extreme weight control behaviors, such as diet pill use or self-induced vomiting, were used by $11.7 \%$ and $10.0 \%$ of young adults practicing and not practicing yoga, respectively. Less extreme unhealthy weight control behaviors, such as meal skipping or fasting, were used by $51.0 \%$ and $55.9 \%$ of those practicing and not practicing yoga, respectively. Binge eating was reported by $10.9 \%$ of yoga practitioners and $10.3 \%$ of those not practicing yoga. After further adjustment for BMI, young adults practicing yoga were more likely to engage in less extreme unhealthy weight control behaviors than those not practicing yoga (Model 2 adjusted proportions: $62.4 \%$ vs. $50.8 \%, E S=0.24, p$ $=.01)$.

Use of steroids or protein powder/shakes to increase muscle size or tone were reported by $1.8 \%$ and $27.0 \%$ of all study participants, respectively. The use of these muscle-enhancing behaviors was higher among young adults practicing yoga than those not practicing (Table 2 ). Among those practicing yoga, $4.2 \%$ used steroids as compared to $0.8 \%$ of 
those not practicing yoga $(E S=0.23, p<.001$ ). Furthermore, $35.4 \%$ of young adults practicing yoga used protein powder or shakes in the past year as compared to $25.0 \%$ of those not practicing yoga $(E S=0.23, p=.005)$.

Given the direction and magnitude of the association between yoga and muscle-enhancing behaviors, and the thought that this association may reflect a higher overall level of physical activity among yoga practitioners, we further explored whether the associations between yoga practice and muscle-enhancing behaviors were maintained after adjustment for overall levels of moderate-to-vigorous physical activity levels, in addition to socio-demographic characteristics. Associations remained statistically significant (steroids: $p<.001$; protein powders/shakes: $p=.029$ ). In analyses, additionally adjusted for BMI category, associations also remained significant (steroids: $p<.001$; protein powders/shakes: $p=.034$ ). This finding suggests the association between yoga practice and muscle-enhancing behaviors is independent of overall levels of physical activity and BMI category.

Associations were further examined to assess if there was a dose-response relationship between frequency of practicing yoga and the various outcomes. No statistically significant dose-response relationships were found in analyses adjusted for sociodemographic characteristics and additionally adjusted for weight status. Thus, the abovementioned associations did not differ in accordance with the frequency of practice.

\section{Interactions with structurally racialized categories - ethnicity/race}

In order to determine if associations between yoga practice and the different outcomes were similar across ethnicity/race, interactions with yoga and ethnicity/race were examined. As shown in Table 3, in analyses, patterns were similar across ethnicity/race and there were no statistically significant interactions. Small numbers (e.g., cell sizes $<5)$ precluded testing interactions with ethnicity/race for less prevalent outcomes: binge eating, extreme unhealthy weight control, and steroid use. 
Table 3

Body image related variables by yoga practice by structurally racialized categories (interaction by ethnicity/race)

Model $1^{1}$

Model $2^{2}$

Yoga Practice

No $(n=1334) \quad$ Yes $(n=209) \quad$ ES $\quad \begin{aligned} & p- \\ & \text { value }\end{aligned}$ ES $\quad \begin{aligned} & p \text { - } \\ & \text { value }\end{aligned}$

Mean (SE) or \% Mean (SE) or \%

$(\mathrm{N})$

$(\mathrm{N})$

Body satisfaction

\begin{tabular}{|c|c|c|c|c|c|c|}
\hline White & $42.2(0.74)$ & $45.5(1.75)$ & 0.27 & 0.069 & 0.14 & 0.320 \\
\hline Black & $45.8(0.74)$ & $47.0(2.28)$ & 0.10 & 0.618 & -0.10 & 0.627 \\
\hline Hispanic & $39.9(0.80)$ & $41.7(2.00)$ & 0.14 & 0.415 & 0.06 & 0.699 \\
\hline Asian & $36.8(0.66)$ & $41.5(2.00)$ & 0.38 & 0.026 & 0.25 & 0.116 \\
\hline Native American & $42.2(1.87)$ & $37.9(8.66)$ & -0.35 & 0.623 & -0.58 & 0.410 \\
\hline Other & $43.7(1.15)$ & $44.6(1.86)$ & 0.07 & 0.651 & 0.02 & 0.910 \\
\hline Interaction p-value & & & & 0.73 & & 0.67 \\
\hline \multicolumn{7}{|l|}{ Mindful eating } \\
\hline White & $11.2(0.13)$ & $11.9(0.29)$ & 0.35 & 0.018 & 0.32 & 0.034 \\
\hline Black & $11.5(0.13)$ & $12.1(0.30)$ & 0.27 & 0.082 & 0.25 & 0.115 \\
\hline Hispanic & $12.0(0.14)$ & $11.8(0.27)$ & -0.09 & 0.560 & -0.10 & 0.506 \\
\hline Asian & $11.6(0.12)$ & $11.8(0.34)$ & 0.09 & 0.584 & 0.02 & 0.931 \\
\hline Native American & $11.9(0.25)$ & $12.5(0.25)$ & 0.28 & 0.103 & 0.21 & 0.247 \\
\hline Other & $11.9(0.22)$ & $12.9(0.32)$ & 0.44 & 0.016 & 0.51 & 0.007 \\
\hline Interaction p-value & & & & 0.19 & & 0.13 \\
\hline \multicolumn{7}{|l|}{ BMI } \\
\hline White & $26.4(0.37)$ & $25.9(1.17)$ & -0.08 & 0.654 & - & - \\
\hline Black & $27.1(0.44)$ & $24.2(0.70)$ & -0.42 & 0.000 & - & - \\
\hline Hispanic & $28.2(0.48)$ & $26.4(0.86)$ & -0.25 & 0.079 & - & - \\
\hline Asian & $27.4(0.39)$ & $24.7(1.00)$ & -0.40 & 0.010 & - & - \\
\hline Native American & $27.8(0.91)$ & $24.4(1.57)$ & -0.49 & 0.060 & - & - \\
\hline Other & $27.8(0.72)$ & $27.0(1.21)$ & -0.12 & 0.539 & - & - \\
\hline Interaction p-value & & & & 0.47 & & - \\
\hline
\end{tabular}

${ }^{1}$ Model 1 is adjusted for age, gender, ethnicity/race, and socio-economic status.

2 Model 2 is additionally adjusted for Body Mass Index category. 
Less extreme unhealthy weight control behaviors

\begin{tabular}{|lllllll|}
\hline White & $42.3 \%(3.09)$ & $52.6 \%(7.09)$ & 0.21 & 0.164 & 0.38 & 0.030 \\
\hline Black & $50.9 \%(3.10)$ & $40.8 \%(8.00)$ & -0.20 & 0.249 & -0.06 & 0.765 \\
\hline Hispanic & $47.9 \%(3.43)$ & $61.1 \%(8.44)$ & 0.27 & 0.157 & 0.20 & 0.053 \\
\hline Asian & $63.3 \%(2.85)$ & $68.0 \%(8.24)$ & 0.10 & 0.597 & 0.31 & 0.118 \\
\hline Native American & $60.6 \%(6.77)$ & $72.4 \%(24.7)$ & 0.25 & 0.662 & 0.30 & 0.638 \\
\hline Other & $46.2 \%(4.56)$ & $56.8 \%(8.71)$ & 0.21 & 0.279 & 0.22 & 0.314 \\
\hline Interaction p-value & & & 0.46 & 0.59 \\
\hline Protein powder & & & & \\
\hline White & $22.8 \%(2.76)$ & $33.6 \%(6.61)$ & 0.24 & 0.098 & 0.27 & 0.097 \\
\hline Black & $24.5 \%(2.71)$ & $32.9 \%(7.92)$ & 0.19 & 0.291 & 0.18 & 0.303 \\
\hline Hispanic & $32.3 \%(3.23)$ & $32.8 \%(8.49)$ & 0.01 & 0.956 & 0.04 & 0.887 \\
\hline Asian & $22.3 \%(2.57)$ & $30.6 \%(8.39)$ & 0.19 & 0.308 & 0.16 & 0.445 \\
\hline Native American & $20.9 \%(5.57)$ & $21.4 \%(19.8)$ & 0.01 & 0.981 & 0.00 & 0.992 \\
\hline Other & $25.3 \%(4.06)$ & $51.7 \%(9.30)$ & 0.55 & 0.008 & 0.56 & 0.010 \\
\hline Interaction p-value & & & 0.57 & 0.60 \\
\hline 1 Model 1 is adjusted for age, gender, ethnicity/race, and socio-economic status. & & & \\
\hline 2 Model 2 is additionally adjusted for Body Mass Index category. & & & \\
\hline
\end{tabular}

\section{Discussion}

The aim of this study was to explore the prevalence of practicing yoga and associations with body image, mindful eating, disordered eating, and muscle-enhancing behaviors in a diverse population-based sample of emerging adults. Findings among this primarily low-income and ethnically/racially diverse population-based sample indicate that yoga practitioners had higher levels of mindful eating and body satisfaction than those not practicing yoga. However, and of concern, young adults practicing yoga had similar levels of unhealthy weight control behaviors and binge eating, and were more likely to use steroids or protein powders/shakes to enhance the size or tone of their muscles than those not practicing yoga. After further adjustment for BMI, which was lower among yoga practitioners than nonpractitioners, yoga practice was not associated with body satisfaction and was associated with higher levels of less extreme unhealthy weight control behaviors. These patterns did not differ significantly across ethnic/racial subgroups of the population. While yoga may offer many health benefits broadly (25-29) and in terms of body image, disordered eating, and weight-related health $(37,57,58)$, it is important that yoga teachers are aware that many of their students may be engaging in unhealthy behaviors aimed at changing their body shape or size. Yoga teachers and yoga practitioners, themselves, can take steps toward the promotion of greater body acceptance and appreciation. 
To the best of our knowledge, this is the first population-based study that has examined associations between yoga practice and the use of muscle enhancers such as steroids or protein powders/shakes. Just over a third of emerging young adults practicing yoga used protein powders or shakes to enhance the size or tone of their muscles. While there is a lack of clarity about what they were consuming and potential adverse health consequences, findings suggest a preoccupation with muscle enhancement. The higher use of steroids to enhance muscles among yoga practitioners is of great concern, particularly given the known adverse consequences of using steroids (59). While further research in different populations is needed to confirm these findings, results from the current study suggest that yoga teachers would do well to avoid any language likely to increase concerns about physique.

Similarly, it is of concern that equal or higher percentages of young adults practicing yoga engage in disordered eating behaviors as compared to those not practicing yoga. It is promising to see that young adults engaging in disordered eating behaviors are choosing to practice yoga, given the underlying tenets of yoga, in addition to research findings suggesting that yoga may be helpful in terms of promoting a stronger sense of self and positive embodiment (17, 39, 60). Furthermore, some longitudinal and intervention studies have suggested that yoga may be effective in improving body image and disordered eating behaviors $(37,38,57,58,61,62)$. Although findings do not consistently show the benefits of yoga $(30,31)$, we are not aware of research findings showing that yoga can be harmful in terms of worsening these health outcomes. Our findings suggest the need for yoga teachers to be aware of the high percentage of their students who may be engaging in disordered eating behaviors and engage in teaching practices likely to help, and not harm, their students. For example, given that internal critique and comparative critique during yoga class have been identified by yoga practitioners as factors with the potential to harm one's body image, teachers are encouraged to use language to help students focus inward and minimize students' tendencies to make comparisons with either the teacher or other students (14). Furthermore, work by Halliwell and colleagues (37), suggests the value of intentionally inserting language to support an improved body image to enhance the positive impact of yoga (e.g., practicing gratitude for all the things one's body can do or envisioning the body as a guesthouse for the soul).

In the current study, yoga was associated with higher levels of mindful eating. In prior qualitative research, young adults practicing yoga discussed how yoga helped with increased awareness of their bodies' needs, the selection of more nourishing foods, attentiveness to internal signs of hunger or fullness, and greater presence while eating (63). A randomized, controlled trial examining the impact of yoga among adults engaging in binge eating (61), found that yoga was associated with decreased binge eating. Likewise, qualitative interviews with study participants indicated perceived improvements in eating behaviors, including greater presence and mindfulness while eating (64). Further work is needed to determine if yoga can lead to more mindful eating and, in turn can help reduce binge eating behaviors in the general population.

Body satisfaction was found to be higher among emerging adults practicing yoga in analyses adjusted for sociodemographic characteristics but not after further adjustment for weight status. The difference between these two analyses can be attributed to the lower mean BMI among yoga practitioners and the inverse associations that tend to exist in our society between BMI and body satisfaction (65). The first analysis indicates that young adults practicing yoga have higher levels of body satisfaction after adjusting for any differences in socio-demographic characteristics. The second analysis, with additional adjustment for weight status, informs us that if young adults practicing and not practicing yoga were similar with regard to their weight status, there would not be differences in body satisfaction across the groups. What remains unclear from the current analysis is whether young adults with lower BMI values choose to engage in yoga more often than their counterparts, or whether yoga has helped them reduce their BMI. There is some evidence that yoga can help in reducing BMI (66), with two population-based studies suggesting that yoga can help with weight gain prevention $(67,68)$. However, it is also highly likely that the mean difference in BMI between the yoga practitioners and the non-practitioners is due to young adults with lower BMI 
values being more likely to choose to engage in yoga. Persons living in larger bodies may not feel comfortable at some settings in which yoga is taught. For example, in one of these population-based studies, among young adults practicing yoga, those with higher BMI values were less likely to practice at yoga studios than yoga practitioners with lower BMI values (68). Yoga settings need to be proactive in helping persons from diverse backgrounds, and of diverse body shapes, sizes, and abilities, to feel more welcome and comfortable $(39,69-72)$.

Study strengths and limitations should be taken into account in interpreting the findings. An important strength of the current study is the large size and diverse nature of the study population. There has been a dearth of research on yoga among low-income and ethnically/racially diverse populations. The assessment of a broad array of attitudes and behaviors related to body image is also a study strength. We are unaware of any studies that have examined yoga in relation to muscle enhancing behaviors in any population-based studies. Young people from diverse ethnic/racial and low socio-economic backgrounds have been found to be at high risk for problematic eating and weight-related outcomes $(2,7-11)$, but may be underserved with regard to prevention and treatment interventions $(73,74)$. It is crucial to learn more about how to help in promoting a healthy body image and prevent and reduce unhealthy muscleenhancing and disordered eating behaviors among diverse and potentially underserved populations.

While the diverse nature of the study population is a study strength, it is important to note that in order to properly examine patterns of relatively rare behaviors (e.g., steroid use) by yoga practice, within separate ethnic/racial groups, larger numbers will be needed. Likewise, while utilizing a community-based sample allows for a determination of who is practicing yoga, the mean frequency of practicing yoga among such a broad sample tends to be low, with relatively few respondents reporting practicing an average of more than two hours a week. While we conducted a dose-response analysis, and did not see trends suggesting that those practicing more often were better off, the numbers of young adults practicing frequently was low, leading us to interpret the findings cautiously. Additionally, the cross-sectional nature of the study needs to be considered in interpreting findings; inferences about directionality of associations or causation cannot be inferred. Further longitudinal work is needed to detect changes over time following a consistent period of yoga practice. Finally, it is important to replicate these findings in other study populations and to examine differences in associations by characteristics of the yoga practice (e.g., intensity, focus), teaching styles, and locations of practice (e.g., home vs. studio). As previously noted, we are unaware of any other studies that have examined muscle enhancing behaviors in population-based samples and it will be important to replicate our findings and explore in more depth.

\section{Conclusion}

In summary, among a large population-based sample of emerging adults from diverse ethnic/racial and socioeconomic backgrounds, disordered eating and muscle-enhancing behaviors were equally or more common among young adults practicing yoga as compared to those not practicing yoga. In order to promote yoga among diverse populations, and enhance its safety and benefits, it is crucial for settings in which yoga is offered, and yoga teachers, to have awareness of the high prevalence of these concerning behaviors among students and to address accordingly. Certainly, these settings should not be promoting products aimed at muscle enhancement such as protein powders and shakes. For those practicing yoga on their own, it may also be helpful to learn to how to focus more on the process of coming inward during one's yoga practice to enhance the potential for yoga's positive impact on overall well-being. Increased awareness to self-critique and replacing potentially harmful self-dialogues with increased positive self-talk and greater self-compassion may also enhance the positive impact of one's yoga practice. Further research exploring yoga practice among diverse populations is needed, including studies that include more details on muscle-enhancing products being used and reasons for using these products; longitudinal studies to examine changes in body image attitudes and behaviors following a consistent yoga practice; qualitative research to better

Page 14/19 
understand yoga practitioners' perceptions how the practice of yoga could be enhanced to improve body image and related behaviors; and intervention studies to examine the impact on outcomes of interest of yoga taught in different manners.

DECLARATIONS

\section{Declarations}

\section{Ethics approval and consent to participate}

The University of Minnesota's Institutional Review Board Human Subjects Committee approved all protocols used. Committee reference number: 1101S94792.

\section{Consent for publication}

Not applicable.

\section{Availability of data and materials}

Investigators interested in utilizing the dataset used in the current study should contact the corresponding author.

\section{Competing interests}

The authors declare that they have no competing interests.

\section{Funding}

This study was supported by the National Heart, Lung, and Blood Institute through grant numbers R01HL127077 and R35HL139853 (PI: D. Neumark-Sztainer). The content is solely the responsibility of the authors and does not necessarily represent the official views of the National Heart, Lung, and Blood Institute and the National Institutes of Health.

\section{Authors' contributions}

DNS is Principal Investigator of the study, conceptualized the manuscript, and wrote all drafts of the manuscript. MMW is a Co-Investigator on the study and contributed to data analysis and interpretation of the data. JC conducted data analysis for this study. DJB, NL, and ME are Co-Investigators on the study and contributed to study design, study implementation, interpretation of the findings, and manuscript writing. All authors critically reviewed and approved the manuscript and agree to be accountable for all aspects of the work regarding the accuracy or integrity of any part of the work.

\section{Acknowledgements}

Not applicable.

\section{References}


1. Neumark-Sztainer D, Wall MM, Chen C, Larson NI, Christoph MJ, Sherwood NE. Eating, activity, and weight-related problems from adolescence to adulthood. Am J Prev Med. 2018;55(2):133-41.

2. Neumark-Sztainer D, Wall MM, Larson N, Story M, Fulkerson JA, Eisenberg ME, et al. Secular trends in weight status and weight-related attitudes and behaviors in adolescents from 1999 to 2010. Prev Med. 2012;54(1):7781.

3. Chin SN, Laverty AA, Filippidis FT. Trends and correlates of unhealthy dieting behaviours among adolescents in the United States, 1999-2013. BMC Public Health. 2018;18(1):439.

4. Nagata JM, Garber AK, Tabler JL, Murray SB, Bibbins-Domingo K. Prevalence and correlates of disordered eating behaviors among young adults with overweight or obesity. J Gen Intern Med. 2018;33(8):1337-43.

5. Nagata JM, Garber AK, Tabler J, Murray SB, Vittinghoff E, Bibbins-Domingo K. Disordered eating behaviors and cardiometabolic risk among young adults with overweight or obesity. Int J Eat Disord. 2018;51(8):931-41.

6. Hart LM, Gordon AR, Sarda V, Calzo JP, Sonneville KR, Samnaliev M, et al. The association of disordered eating with health-related quality of life in U.S. young adults and effect modification by gender. Qual Life Res. 2020:113.

7. Eisenberg ME, Wall M, Neumark-Sztainer D. Muscle-enhancing behaviors among girls and boys. Pediatrics. 2012;130(6):1019-26.

8. Tester JM, Lang TC, Laraia BA. Disordered eating behaviours and food insecurity: A qualitative study about children with obesity in low-income households. Obesity Res Clin Prac. 2016;10(5):544-52.

9. West CE, Goldschmidt AB, Mason SM, Neumark-Sztainer D. Differences in risk factors for binge eating by socioeconomic status in a community-based sample of adolescents: Findings from Project EAT. Int J Eat Disord. 2019;52(6):659-68.

10. Buckingham-Howes S, Armstrong B, Pejsa-Reitz MC, Wang Y, Witherspoon DO, Hager ER, et al. BMI and disordered eating in urban, African American, adolescent girls: The mediating role of body dissatisfaction. Eat Behav. 2018;29:59-63.

11. Najjar RH, Jacob E, Evangelista L. Eating behaviors, weight bias, and psychological functioning in multi-ethnic low-income adolescents. J Pediatr Nurs. 2018;38:81-7.

12. Kraftsow G. Yoga for transformation: Ancient teachings and Holistic practices for healing body, mind, and heart. New York: Penguin Compass; 2002. xxvii-257.

13. Cook-Cottone CP. Mindfulness and yoga for self-regulation: A primer for mental health professionals. New York: Springer Publishing Company; 2015. xxiii-322.

14. Neumark-Sztainer D, Watts AW, Rydell S. Yoga and body image: How do young adults practicing yoga describe its impact on their body image? Body Image. 2018;27:156-68.

15. Dittmann KA, Freedman MR. Body awareness, eating attitudes, and spiritual beliefs of women practicing yoga. Eat Disord. 2009;17(4):273-92.

16. Neumark-Sztainer D. Yoga and eating disorders: Is there a place for yoga in the prevention and treatment of eating disorders and disordered eating behaviours? Adv Eating Disord. 2014;2(2):136-45.

17. Piran N, Neumark-Sztainer D. Yoga and the experience of embodiment: A discussion of possible links. Eat Disord. 2020:1-19.

18. Cox AE, Tylka TL. A conceptual model describing mechanisms for how yoga practice may support positive embodiment. Eat Disord. 2020:1-24.

19. Impett EA, Daubenmier JJ, Hirschman AL. Minding the body: Yoga, embodiment, and well-being. Sex Res Social Policy. 2006;3(4):39-48. 
20. Birdee GS, Legedza AT, Saper RB, Bertisch SM, Eisenberg DM, Phillips RS. Characteristics of yoga users: Results of a national survey. J Gen Intern Med. 2008;23(10):1653-8.

21. Cramer H, Ward L, Steel A, Lauche R, Dobos G, Zhang Y. Prevalence, patterns, and predictors of yoga use: Results of a U.S. nationally representative survey. Am J Prev Med. 2016;50(2):230-5.

22. Saper RB, Eisenberg DM, Davis RB, Culpepper L, Phillips RS. Prevalence and patterns of adult yoga use in the United States: results of a national survey. Altern Ther Health Med. 2004;10(2):44-9.

23. Peregoy J, Clarke T, Jones L, Stussman B, Nahin R. Regional variation in use of complementary health approaches by U.S. adults. NCHS data brief, no 146. National Center for Health Statistics: Hyattsville, MD. 2014.

24. Clarke TC, Barnes P, Black L, Stussman B, Nahin R. Use of yoga, meditation, and chiropractors among U.S. adults aged 18 and over. NCHS Data Brief. 2018(325):1-8.

25. Bussing A, Michalsen A, Khalsa SB, Telles S, Sherman KJ. Effects of yoga on mental and physical health: A short summary of reviews. Evidence-Based Complement Alternat Med. 2012:165410.

26. Macy RJ, Jones E, Graham LM, Roach L. Yoga for trauma and related mental health problems: A meta-review with clinical and service recommendations. Trauma Violence Abuse. 2018;19(1):35-57.

27. Maroik S, Hazari CS, Mondal BC. Effect of yoga on health. Int J Yoga Physiotherapy Phys Educ. 2017;2(2):75-7.

28. McCall MC, Ward A, Roberts NW, Heneghan C. Overview of systematic reviews: Yoga as a therapeutic intervention for adults with acute and chronic health conditions. Evidence-Based Complement Alternat Med. 2013;2013.

29. Jeter PE, Slutsky J, Singh N, Khalsa SBS. Yoga as a therapeutic intervention: A bibliometric analysis of published research studies from 1967 to 2013. J Alternat Complement Med. 2015;21(10):586-92.

30. Domingues RB, Carmo C. Disordered eating behaviours and correlates in yoga practitioners: a systematic review. Eating and Weight Disorders-Studies on Anorexia, Bulimia and Obesity. 2019:1-10.

31. Ostermann T, Vogel H, Boehm K, Cramer H. Effects of Yoga on eating disorders-A systematic review. Complement Ther Med. 2019.

32. Scime M, Cook-Cottone C, Kane L, Watson T. Group prevention of eating disorders with fifth-grade females: Impact on body dissatisfaction, drive for thinness, and media influence. Eat Disord. 2006;14(2):143-55.

33. Klein J, Cook-Cottone C. The effects of yoga on eating disorder symptoms and correlates: A review. Int J Yoga Therapy. 2013(23):41-50.

34. Diers L, Rydell S, Watts A, Neumark-Stzainer D. A yoga-based therapy program designed to improve body image among an outpatient eating disordered population: Program description and results from a pilot study. Eat Disord. 2020. [Epub ahead of print].

35. Kramer R, Cuccolo K. Yoga practice in a college sample: Associated changes in eating disorder, body image, and related factors over time. Eat Disord. 2019:1-19.

36. Pacanowski CR, Diers L, Crosby RD, Mackenzie M, Neumark-Stzainer D. Yoga's impact on risk and protective factors for disordered eating: a pilot prevention trial. Eat Disord. 2020. [Epub ahead of print].

37. Halliwell E, Dawson K, Burkey S. A randomized experimental evaluation of a yoga-based body image intervention. Body Image. 2019;28:119-27.

38. Neumark-Sztainer D, MacLehose RF, Watts AW, Pacanowski CR, Eisenberg ME. Yoga and body image: Findings from a large population-based study of young adults. Body Image. 2018;24:69-75.

39. Webb JB, Rogers CB, Thomas EV. Realizing yoga's all-access pass: A social justice critique of westernized yoga and inclusive embodiment. Eat Disord. 2020:1-27. 
40. Larson NI, Wall MM, Story MT, Neumark-Sztainer DR. Home/family, peer, school, and neighborhood correlates of obesity in adolescents. Obesity (Silver Spring). 2013;21(9):1858-69.

41. Arcan C, Larson N, Bauer K, Berge J, Story M, Neumark-Sztainer D. Dietary and weight-related behaviors and body mass index among Hispanic, Hmong, Somali, and White adolescents. J Acad Nutr Diet. 2014;114(3):375-83.

42. Little RJA. Survey nonresponse adjustments for estimates of means. Int Stat Rev. 1986;54(2):139-57.

43. Seaman S, White I. Review of inverse probability weighting for dealing with missing data. Stat Methods Med Res. 2011;22(3):278-95.

44. Bucchianeri MM, Eisenberg ME, Neumark-Sztainer D. Weightism, racism, classism, and sexism: Shared forms of harassment in adolescents. J Adolesc Health. 2013;53(1):47-53.

45. Neumark-Sztainer D, Wall M, Fulkerson JA, Larson N. Changes in the frequency of family meals from 1999 to 2010 in the homes of adolescents: trends by sociodemographic characteristics. J Adolesc Health.

2013;52(2):201-6.

46. Neumark-Stzainer D, Wall M, Choi J, Barr-Anderson D, Telke S, Mason SM. Exposure to adverse events and associations with stress levels and the practice of yoga: Survey findings from a population-based study of diverse emerging young adults. J Altern Complement Med. 2020. [Epub ahead fo print].

47. Pingitore R, Spring B, Garfield D. Gender differences in body satisfaction. Obes Res. 1997;5(5):402-9.

48. Framson C, Kristal AR, Schenk JM, Littman AJ, Zeliadt S, Benitez D. Development and validation of the mindful eating questionnare. J Am Diet Assoc. 2009;109:1439-44.

49. Yanovski SZ. Questionnaire on Eating and Weight Patterns-Revised (QEWP-R). Obes Res. 1993;1:319-24.

50. Field AE, Austin SB, Camargo CA, Taylor CB, Striegel-Moore RH, Loud KJ, et al. Exposure to the mass media, body shape concerns, and use of supplements to improve weight and shape among male and female adolescents.

Pediatrics. 2005;116(2):e214-e20.

51. Ricciardelli LA, McCabe MP. Psychometric evaluation of the Body Change Inventory: An assessment instrument for adolescent boys and girls. Eat Behav. 2002;3(1):45-59.

52. Eisenberg ME, Wall M, Shim JJ, Bruening M, Loth K, Neumark-Sztainer D. Associations between friends' disordered eating and muscle-enhancing behaviors. Soc Sci Med. 2012;75(12):2242-9.

53. Godin G, Shephard R. A simple method to assess exercise behavior in the community. Can J Appl Sport Sci. 1985;10(3):141-6.

54. Sherwood NE, Wall M, Neumark-Sztainer D, Story M. Effect of socioeconomic status on weight change patterns in adolescents. Prev Chronic Dis. 2009;6(1):A19.

55. Neumark-Sztainer D, Story M, Hannan PJ, Croll J. Overweight status and eating patterns among adolescents: where do youths stand in comparison with the healthy people 2010 objectives? Am J Public Health. 2002;92(5):844-51.

56. Cohen J. Statistical Power Analysis for the Behavioral Sciences. 2nd ed. Hillside: Lawrence Erlbaum; 1988.

57. Ariel-Donges AH, Gordon EL, Bauman V, Perri MG. Does yoga help college-aged women with body-image dissatisfaction feel better about their bodies? Sex Roles. 2019;80(1-2):41-51.

58. Cox AE, Ullrich-French S, Howe HS, Cole AN. A pilot yoga physical education curriculum to promote positive body image. Body Image. 2017;23:1-8.

59. Department of Health and Human Services. Anabolic steroid abuse. NIDA Research Report Series. Washington, DC: National Institutes of Health; 2000 April. Report No.: NIH Publication No. 00-3721. 
60. Mahlo L, Tiggemann M. Yoga and positive body image: A test of the Embodiment Model. Body Image. 2016;18:135-42.

61. Mclver S, O'Halloran P, McGartland M. Yoga as a treatment for binge eating disorder: A preliminary study. Complement Ther Med. 2009;17(4):196-202.

62. Brennan MA, Whelton WJ, Sharpe D. Benefits of yoga in the treatment of eating disorders: Results of a randomized controlled trial. Eat Disord. 2020:1-20.

63. Watts AW, Rydell SA, Eisenberg ME, Laska MN, Neumark-Sztainer D. Yoga's potential for promoting healthy eating and physical activity behaviors among young adults: A mixed-methods study. Int J Behav Nutr Phys Act. 2018;15(1):42.

64. Mclver S, McGartland M, O'Halloran P. "Overeating is not about the food": Women describe their experience of a yoga treatment program for binge eating. Qual Health Res. 2009;19(9):1234-45.

65. Weinberger N-A, Kersting A, Riedel-Heller SG, Luck-Sikorski C. Body dissatisfaction in individuals with obesity compared to normal-weight individuals: A systematic review and meta-analysis. Obesity Facts. 2016;9(6):42441.

66. Lauche R, Langhorst J, Lee MS, Dobos G, Cramer H. A systematic review and meta-analysis on the effects of yoga on weight-related outcomes. Prev Med. 2016:87-312-32.

67. Kristal AR, Littman AJ, Benitez D, White E. Yoga practice is associated with attenuated weight gain in healthy, middle-aged men and women. Altern Ther Health Med. 2005;11(4):28-33.

68. Neumark-Sztainer D, MacLehose RF, Watts AW, Eisenberg ME, Laska MN, Larson N. How is the practice of yoga related to weight status? Population-based findings from Project EAT-IV. J Phys Act Health. 2017;14(12):905-12.

69. Pickett AC, Cunningham GB. Creating inclusive physical activity spaces: The case of body-positive yoga. Res Q Exerc Sport. 2017;88(3):329-38.

70. Cook-Cottone C, Douglass LL. Yoga communities and eating disorders: Creating safe space for positive embodiment. International J of Yoga Therapy. 2017;27(1):87-93.

71. Neumark-Sztainer D. The practice of yoga: Can it help in addressing body image concerns and eating disorders. Handbook of positive body image and embodiment. 2019:326-36.

72. Bondy D. Confessions of a fat, Black, yoga teacher. Decolonizing Yoga. 2014.

73. Waldron EM, Hong S, Moskowitz JT, Burnett-Zeigler I. A systematic review of the demographic characteristics of participants in U.S.-based randomized controlled trials of mindfulness-based interventions. Mindfulness. 2018;9(6):1671-92.

74. Polo AJ, Makol BA, Castro AS, Colón-Quintana N, Wagstaff AE, Guo S. Diversity in randomized clinical trials of depression: A 36-year review. Clin Psychol Rev. 2019;67:22-35. 